\title{
The Effect of Atomic Ordering Transformation of PtNi Nanoparticles on Alkaline Hydrogen Evolution: Unexpected Superior Activity of the Disordered Phase
}

Hengquan Chen, ${ }^{\dagger}$ Guangjin Wang,,${ }^{*}$, Tengyang Gao,${ }^{\dagger}$ Youhu Chen, ${ }^{\$}$ Honggang Liao, ${ }^{* \$}$ Xinliang

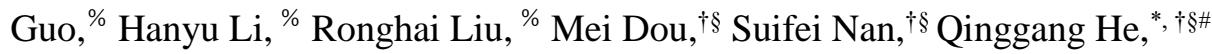

${ }^{\dagger}$ College of Chemical and Biological Engineering, Zhejiang University, Hangzhou, 310027, China

$\S$ Institute of Zhejiang University - Quzhou, 78 Jiuhua Boulevard North, Quzhou, Zhejiang 32400, China.

${ }^{\star}$ School of Materials Science and Energy Engineering, Foshan University, Foshan 528000, China

\$ State Key Lab of Physical Chemistry of Solid Surfaces, Collaborative Innovation Center of Chemistry for Energy Materials, College of Chemistry and Chemical Engineering, Xiamen University, Xiamen 361005, China

${ }^{\%}$ Electric Power Research Institute of Yunnan Power Grid Co., Ltd, Kunming, 650217， China

\# Ningbo Research Institute, Zhejiang University, Ningbo, Zhejiang 315100, China 


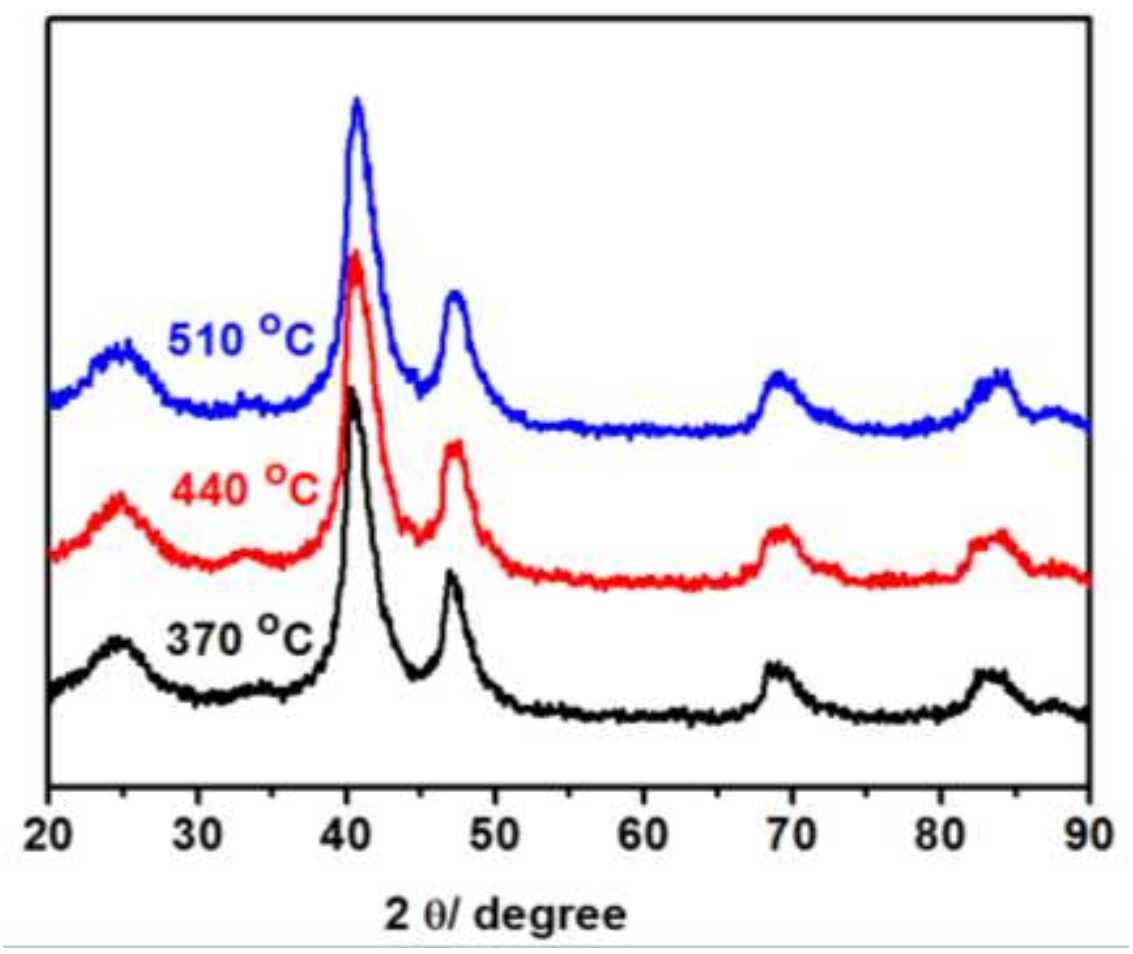

Figure S1 XRD patterns for PtNi/C nanoparticles annealed at $370{ }^{\circ} \mathrm{C}, 440{ }^{\circ} \mathrm{C}$, and $510{ }^{\circ} \mathrm{C}$ 

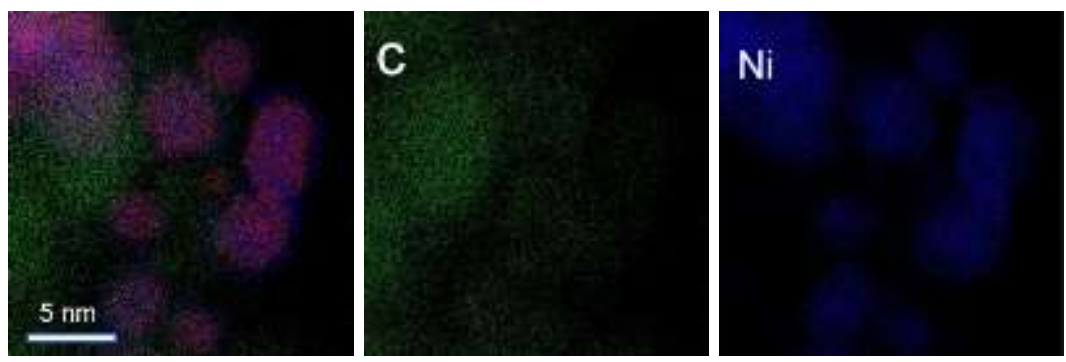

Pt

Figure S2 TEM elemental mapping pictures of D-PtNi/C 


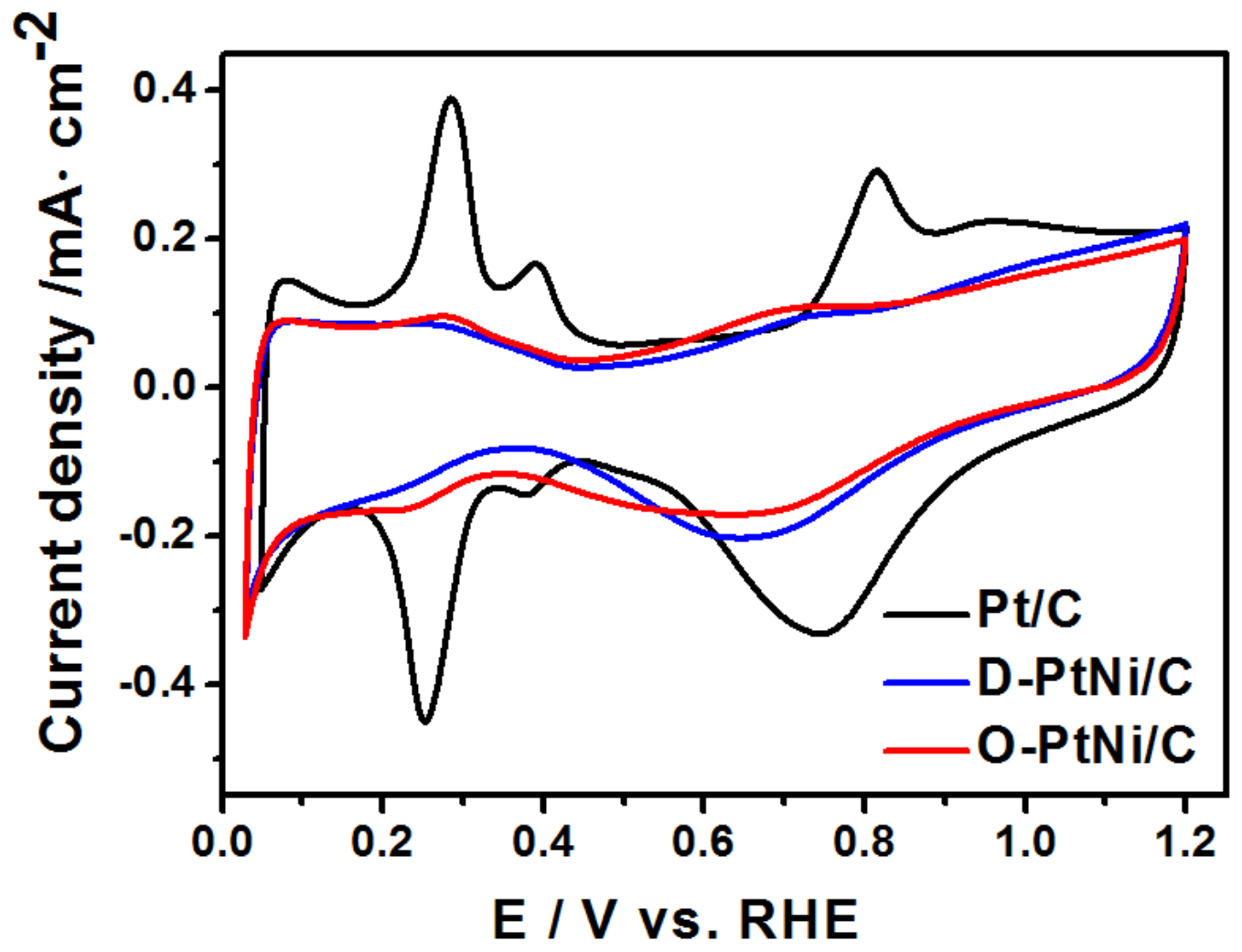

Figure S3 CVs of $\mathrm{Pt} / \mathrm{C}, \mathrm{D}-\mathrm{PtNi} / \mathrm{C}$ and $\mathrm{O}-\mathrm{PtNi} / \mathrm{C}$ in Ar-saturated $1 \mathrm{M} \mathrm{KOH}$ solution at a scan rate of $20 \mathrm{mV} \cdot \mathrm{s}^{-1}$. The Pt loading for all three catalysts on the electrode is 28.3 $\mu \mathrm{g}_{\mathrm{Pt}} \cdot \mathrm{cm}^{-2}$. 


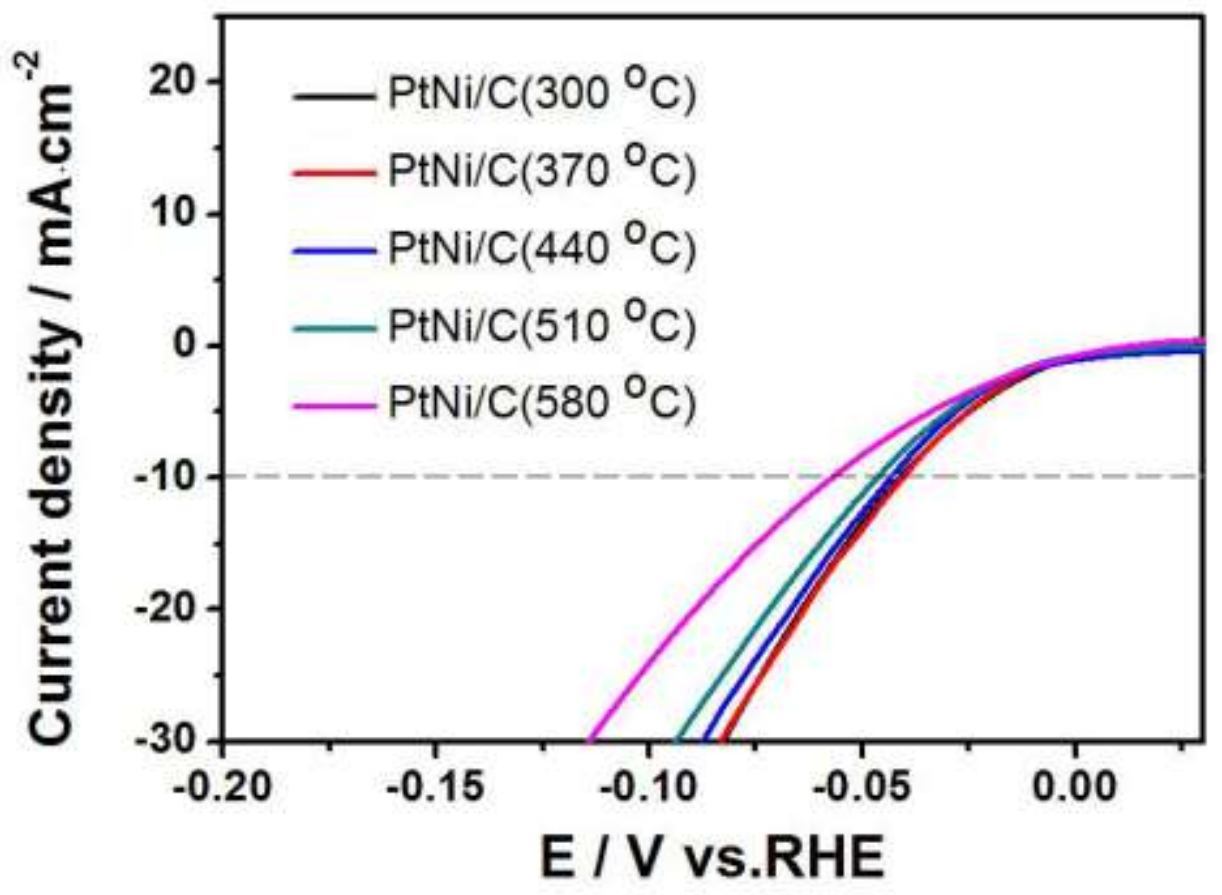

Figure S4 HER polarization curve of PtNi/C nanoparticles in an Ar-saturated 1.0 M KOH solution at a scan rate of $5 \mathrm{mV} \cdot \mathrm{s}^{-1}$. The Pt loading for all three catalysts on the electrode is $28.3 \mu \mathrm{g}_{\mathrm{P}} \cdot \mathrm{cm}^{-2}$ (without $I R$ compensation). 


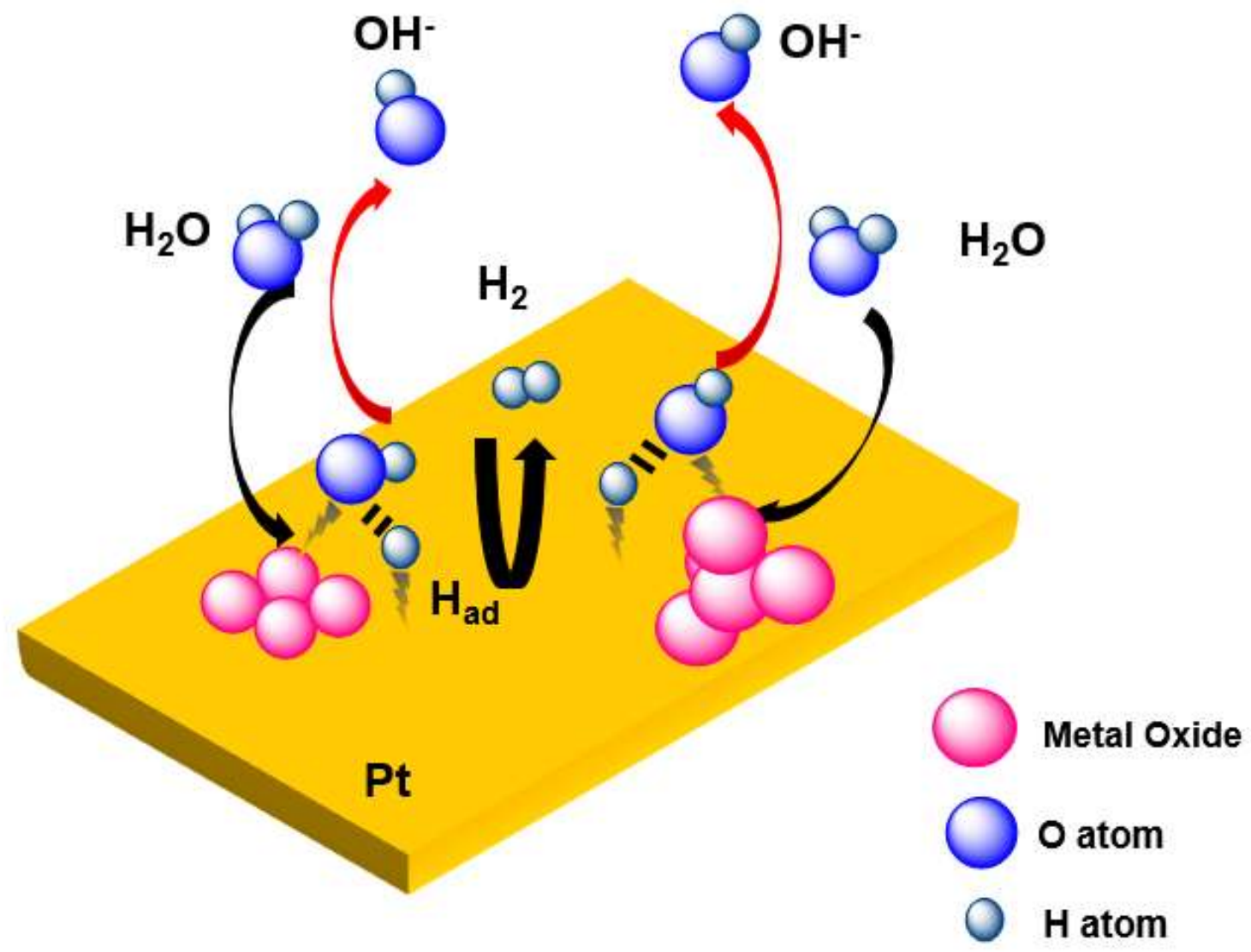

Figure S5 The mechanism of bifunctional effect of transition metal oxides on Pt (111) on alkaline HER. 

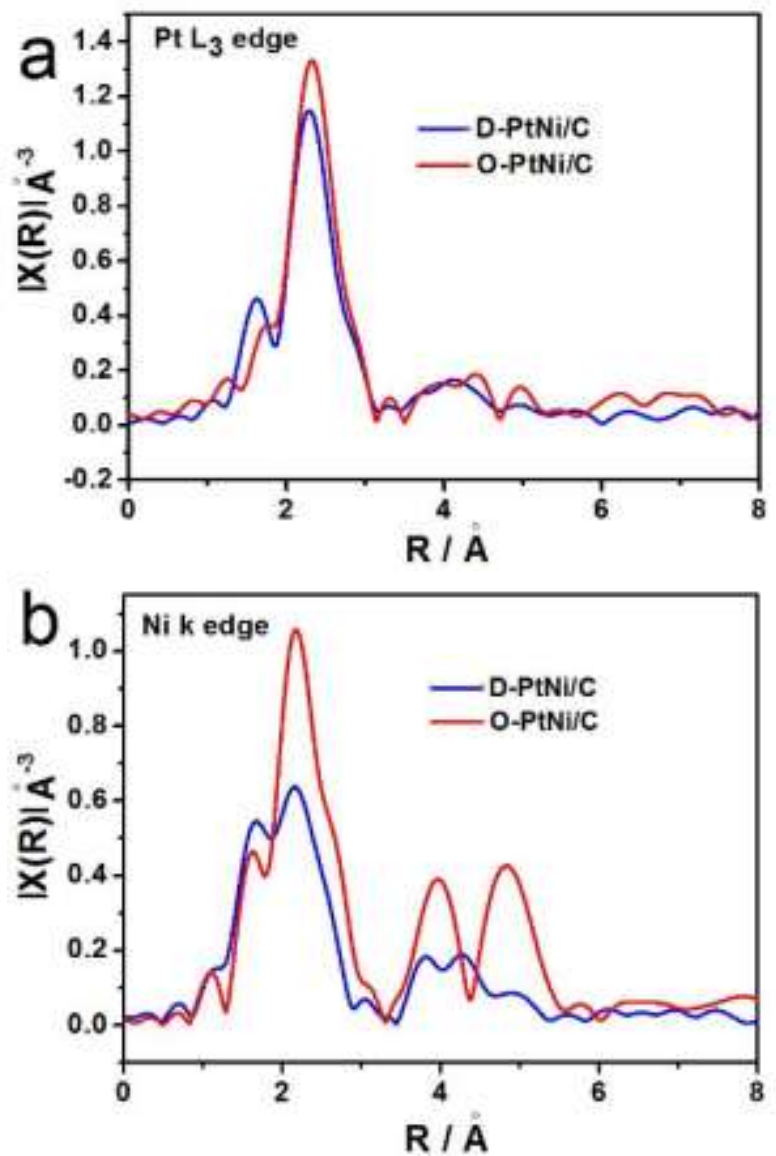

Figure S6 Fourier transforms of EXAFS data at (a) Pt $\mathrm{L}_{3}$-edge, and (b) Ni K-edge of O$\mathrm{PtNi} / \mathrm{C}$ and $\mathrm{D}-\mathrm{PtNi} / \mathrm{C}$ nanoparticles. 

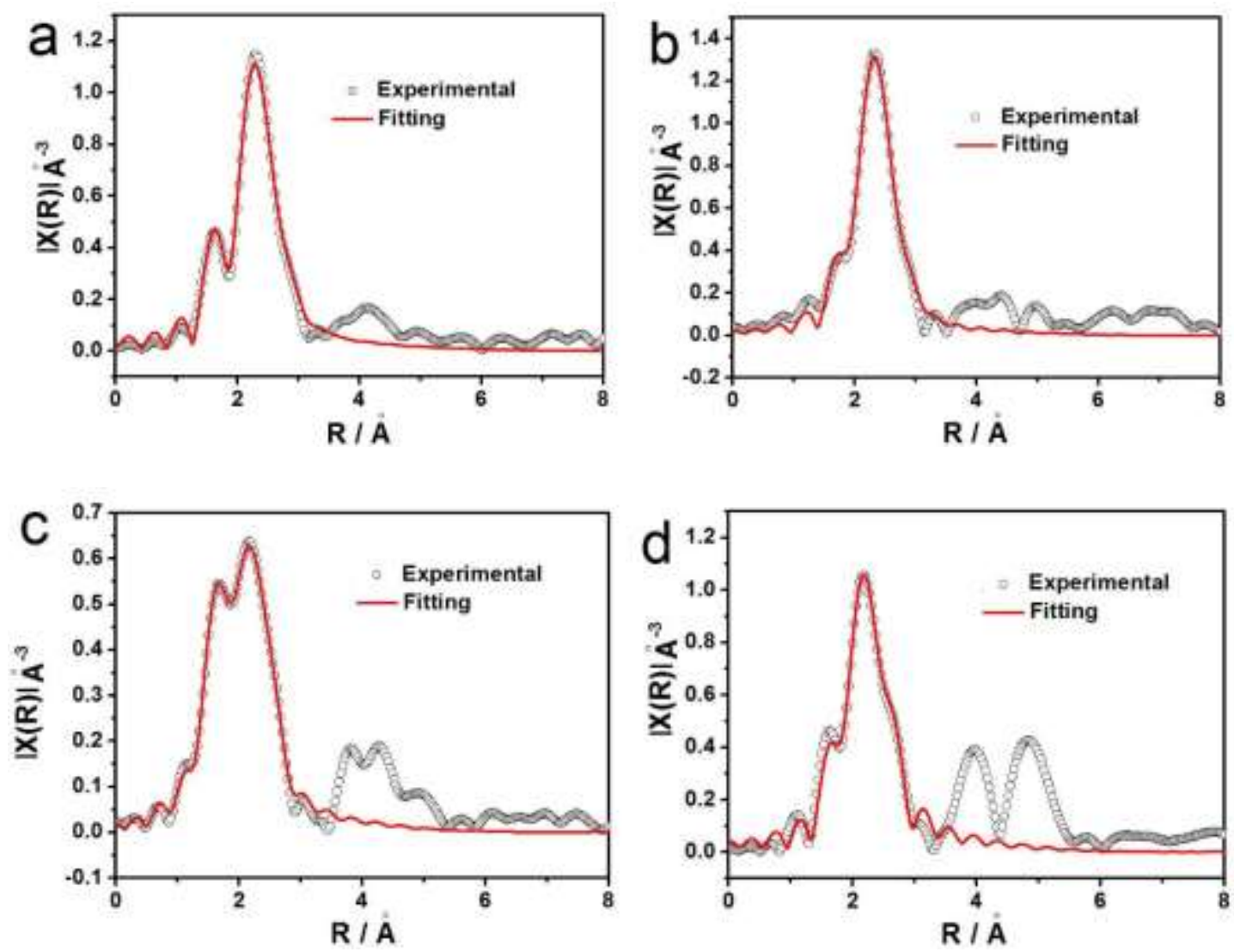

Figure S7 EXAFS fitting curves at $\mathrm{Pt} \mathrm{L}_{3}$-edge of (a) D-PtNi/C and (b) O-PtNi/C, EXAFS fitting curves at Ni K-edge of (c) D-PtNi/C and (d) O-PtNi/C 

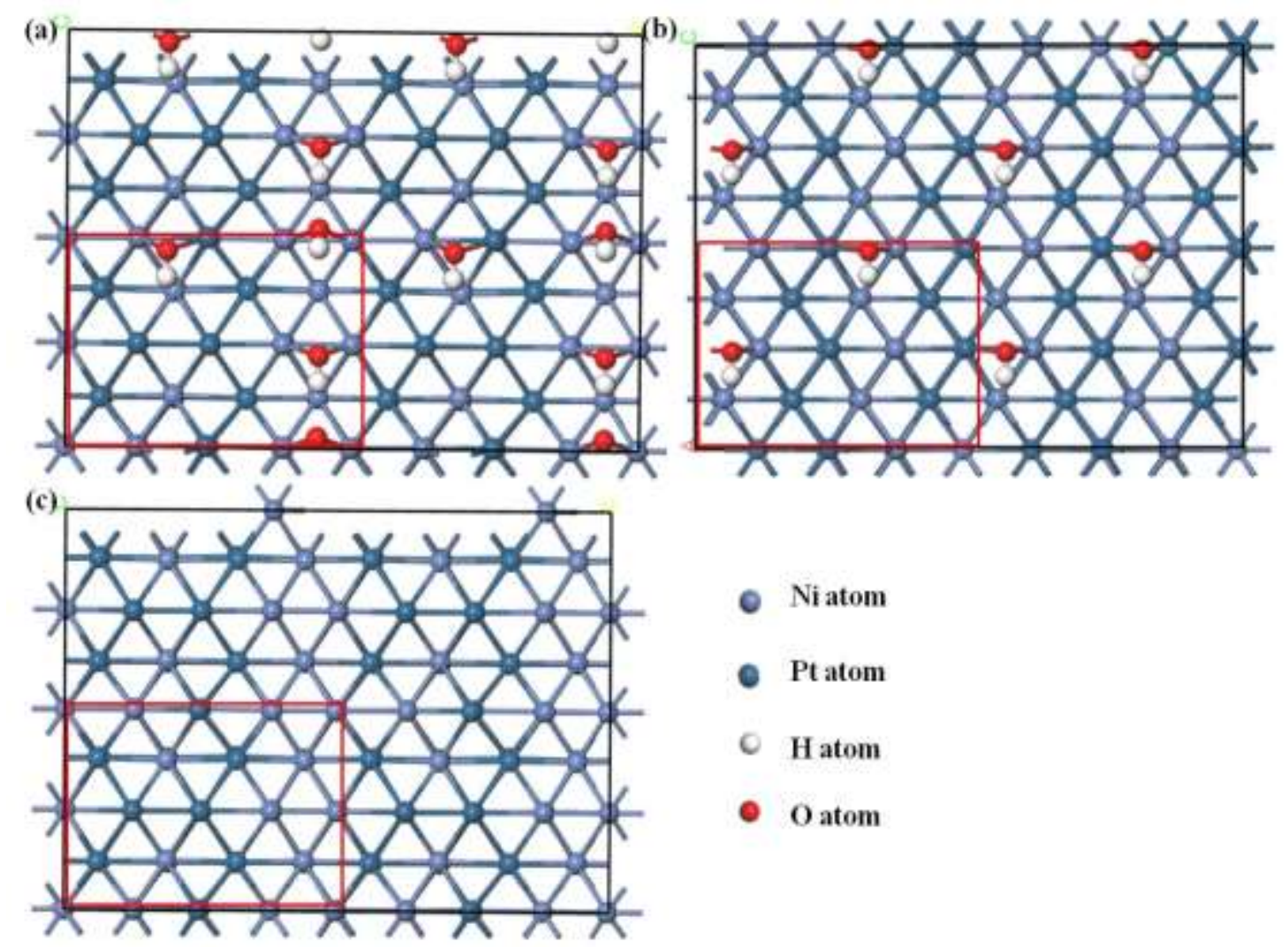

Figure S8 The top view for the atomic configuration of catalyst surfaces (a) D-PtNi, (b) O$\mathrm{PtNi}$ and (c) D-PtNi(i). The red square shows the calculated surface of each catalyst. 


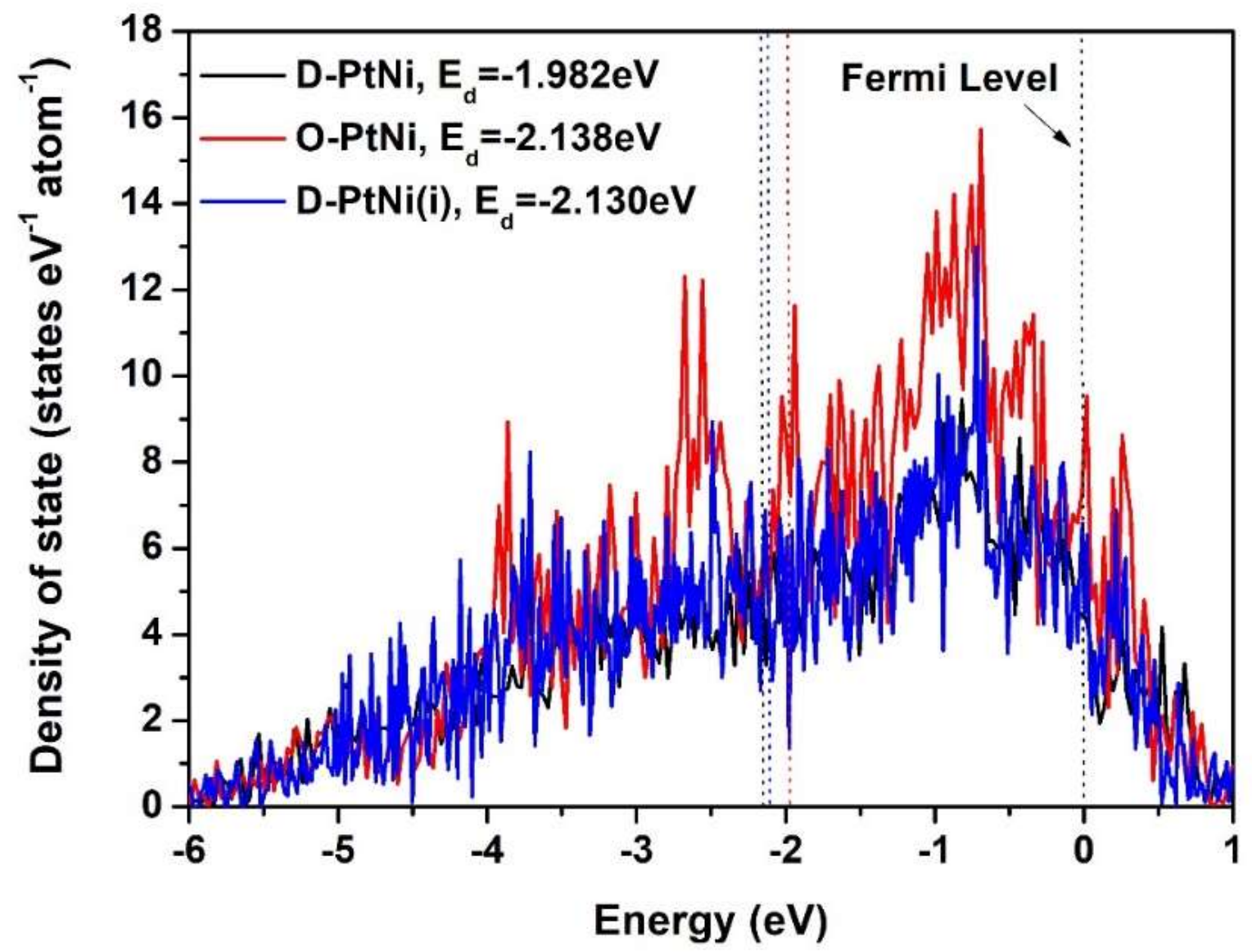

Figure S9 The $d$-electron partial density of states for the metal atoms on the surface of D$\mathrm{PtNi}, \mathrm{O}-\mathrm{PtNi}$ and D-PtNi(i) catalysts where hydrogen atoms were adsorbed 
Table S1. The structural properties of D-PtNi/C, O-PtNi/C and commercial Pt/C

\begin{tabular}{cccccccccc}
\hline \multirow{2}{*}{ Catalysts } & \multirow{2}{*}{$\begin{array}{c}\text { Crystal } \\
\text { structure }\end{array}$} & $\begin{array}{c}\text { Space } \\
\text { group }\end{array}$ & \multicolumn{2}{c}{ Lattice parameter/nm } & \multicolumn{2}{c}{$\begin{array}{c}\text { Structural } \\
\text { Ordering }\end{array}$} & \multicolumn{2}{c}{ Composition } & \multicolumn{2}{c}{$\begin{array}{c}\text { Particle size } \\
\text { /nm }\end{array}$} \\
& & & $\mathrm{a}$ & $\mathrm{b}$ & $\mathrm{c}$ & Ord:Ni & Loading/\% & \\
\hline $\mathrm{Pt} / \mathrm{C}$ & Cubic & $\mathrm{Fm}-3 \mathrm{~m}$ & 0.3920 & 0.3920 & 0.3920 & -- & $1: 0$ & 19.65 & 4.6 \\
$\mathrm{O}-\mathrm{PtNi} / \mathrm{C}$ & Tetragonal & $\mathrm{P} 4 / \mathrm{mmm}$ & 0.3821 & 0.3821 & 0.3588 & ordered & $1: 1.05$ & 21.74 & 8.6 \\
$\mathrm{D}-\mathrm{PtNi} / \mathrm{C}$ & Cubic & $\mathrm{Fm}-3 \mathrm{~m}$ & 0.3742 & 0.3742 & 0.3742 & disordered & $1: 0.97$ & 20.58 & 5.5 \\
\hline
\end{tabular}

Table S2. Particle sizes and overpotentials at $10 \mathrm{~mA} \cdot \mathrm{cm}^{-2}$ of PtNi/C annealed at different temperature

\begin{tabular}{cccc}
\hline Sample & $\begin{array}{c}\text { Annealing temperature } \\
/{ }^{\circ} \mathrm{C}\end{array}$ & Particle size $/ \mathrm{nm}$ & $\eta$ at $10 \mathrm{~mA} \cdot \mathrm{cm}^{-2} / \mathrm{mV}$ \\
\hline PtNi/C-300 & 300 & 5.5 & \\
PtNi/C-370 & 370 & 6.4 & 49.7 \\
PtNi/C-440 & 440 & 6.9 & 42.0 \\
PtNi/C-510 & 510 & 7.2 & 44.5 \\
PtNi/C-580 & 580 & 8.6 & 53.0 \\
\hline
\end{tabular}

Table S3. The surface Pt-to-Ni ratios of O-PtNi/C and D-PtNi/C

\begin{tabular}{cc}
\hline Sample & Pt:Ni \\
\hline D-PtNi/C & $55.34: 44.66$ \\
O-PtNi/C & $64.42: 35.58$
\end{tabular}

*The atomic ratios of $\mathrm{Pt}$ against $\mathrm{Ni}$ on the surfaces of $\mathrm{D}-\mathrm{PtNi} / \mathrm{C}$ and $\mathrm{O}-\mathrm{PtNi} / \mathrm{C}$ are calculated from their XPS spectra. 
Table S4. Pt $\mathrm{L}_{3}$-edge EXAFS curves fitting parameters ${ }^{\mathrm{a}}$

\begin{tabular}{llllll}
\hline Sample & shell & $\mathrm{N}$ & $\mathrm{R}(\AA)$ & $\sigma^{2 *} 10^{3}\left(\AA^{2}\right)$ & R-factor (\%) \\
\hline \multirow{3}{*}{ D-PtNi/C } & Pt-O & $<0.3$ & 1.95 & $/$ & \\
& Pt-Ni & 4.4 & 2.55 & 9.6 & 1.2 \\
& Pt-Pt & 1.3 & 2.69 & 4.1 & \\
\hline \multirow{2}{*}{ O-PtNi/C } & Pt-Ni & 5.1 & 2.55 & 7.5 & \multirow{2}{*}{1.0} \\
& Pt-Pt & 2.9 & 2.69 & 3.0 &
\end{tabular}

${ }^{\mathrm{a}} \Delta \mathrm{k}=3.0-11.0 \AA^{-1}, \Delta \mathrm{r}=1.0-3.0 \AA ; \mathrm{N}$, coordination number; $\mathrm{R}$, distance between absorber and backscatter atoms; $\sigma^{2}$, Debye-Waller factor to account for both thermal and structural disorders; R-factor (\%) indicates the goodness of the fit. The obtained $\mathrm{S}_{0}{ }^{2}$ of $\mathrm{Pt}$ foil was 0.77 and it was fixed in the subsequent fitting of $\mathrm{Pt}_{\mathrm{L}}$-edge data for the catalyst.

Table S5. Ni K-edge EXAFS curves fitting parameters ${ }^{\mathrm{b}}$

\begin{tabular}{llllll}
\hline Sample & shell & $\mathrm{N}$ & $\mathrm{R}(\AA)$ & $\sigma^{2 *} 10^{3}\left(\AA^{2}\right)$ & R-factor (\%) \\
\hline \multirow{3}{*}{ D-PtNi/C } & Ni-O & 1.8 & 2.02 & 6.9 & \\
& $\mathrm{Ni-Ni}$ & 2.1 & 2.50 & 5.3 & 1.1 \\
& $\mathrm{Ni-Pt}$ & 2.4 & 2.55 & 9.8 & \\
\hline \multirow{3}{*}{ O-PtNi/C } & $\mathrm{Ni}-\mathrm{O}$ & 0.4 & 2.00 & 2.9 & \\
& $\mathrm{Ni}-\mathrm{Ni}$ & 2.7 & 2.52 & 1.7 & 0.3 \\
& $\mathrm{Ni}-\mathrm{Pt}$ & 4.1 & 2.56 & 8.8 & \\
\hline
\end{tabular}

${ }^{\mathrm{b}} \Delta \mathrm{k}=3.0-11.0 \AA^{-1}, \Delta \mathrm{r}=1.0-3.0 \AA$; , coordination number; $\mathrm{R}$, distance between absorber and backscatter atoms; $\sigma^{2}$, Debye-Waller factor to account for both thermal and structural disorders; R-factor (\%) indicates the goodness of the fit. The obtained $\mathrm{S}_{0}{ }^{2}$ of $\mathrm{Ni}$ foil was 0.75 and it was fixed in the subsequent fitting of Ni K-edge data for the catalyst. 